Cahiers $d u$ MONDE RUSSE

\section{Cahiers du monde russe}

Russie - Empire russe - Union soviétique et États indépendants

$51 / 4 \mid 2010$

Sciences humaines et sociales en Russie à l'Âge d'argent

\title{
Kenneth B. Moss, Jewish Renaissance in the Russian Revolution
}

\section{Claire Le Foll}

\section{OpenEdition}

\section{Journals}

Édition électronique

URL : https://journals.openedition.org/monderusse/7447

DOI : $10.4000 /$ monderusse. 7447

ISSN : $1777-5388$

Éditeur

Éditions de l'EHESS

\section{Édition imprimée}

Date de publication : 25 novembre 2010

Pagination : 818-821

ISBN : 978-2-7132-2316-7

ISSN : $1252-6576$

\section{Référence électronique}

Claire Le Foll, « Kenneth B. Moss, Jewish Renaissance in the Russian Revolution », Cahiers du monde russe [En ligne], 51/4 | 2010, mis en ligne le 09 décembre 2011, consulté le 03 septembre 2022. URL: http://journals.openedition.org/monderusse/7447 ; DOI : https://doi.org/10.4000/monderusse.7447

Ce document a été généré automatiquement le 3 septembre 2022

Tous droits réservés 


\title{
Kenneth B. Moss, Jewish Renaissance in the Russian Revolution
}

\author{
Claire Le Foll
}

\section{RÉFÉRENCE}

Kenneth B. Moss, Jewish Renaissance in the Russian Revolution. Cambridge -

Londres : Harvard University Press, 2009, 340 p.

1 Avec cet ouvrage, Kenneth Moss offre la première étude approfondie et détaillée sur la vie culturelle juive en Russie pendant la période brève mais extrêmement fertile qui a suivi la révolution de 1917. L'auteur y analyse les principes, réalisations et résultats de la révolution culturelle juive, qui a accompagné la révolution politique russe. Il montre comment des intellectuels, écrivains et artistes juifs ont profité de «ce moment d'ouverture et de vérité » pour mettre en œuvre leur projet culturel de «renaissance juive ». Moss insiste sur le fait qu'il s'agit bien de la réalisation d'un projet, du point culminant d'une démarche qui trouve ses racines dans les décennies précédant la guerre, mais pas d'une rupture et d'une nouvelle vision de la culture juive. Avec la levée de tous les obstacles légaux après février 1917, l'intelligentsia juive a pris conscience que le temps des paroles était révolu et que l'heure était venue de passer à l'action. Les intellectuels dont il est ici question appartenaient à deux camps - hébraïste et «yiddishiste » - et se sont implantés dans deux centres, Moscou et Kiev. Moscou est devenue celui de la culture hébraïste grâce à l'afflux d'acteurs politiques et culturels de divers horizons et à la création du Tarbut, réseau d'organisations sionistes séculières. À Kiev, c'est l'organisation yiddishiste de tendance socialiste Kultur-Lige qui a pu prospérer grâce à une politique du gouvernement ukrainien favorable aux minorités, sans compter que Kiev était un centre de la littérature yiddish avant la révolution. Mais, malgré la distance géographique et le puissant conflit idéologique qui opposait les deux courants, Moss démontre que ces acteurs culturels étaient poussés par la même peur 
d'une assimilation rapide de la population juive et poursuivaient le même but - la création d'une culture juive moderne, radicale et séculière. Grâce à l'analyse minutieuse et subtile des écrits en yiddish, hébreu et russe de ces combattants de la renaissance culturelle juive, l'auteur décrypte les idéaux communs aux yiddishistes et hébraïstes et parvient à reconstituer minutieusement leur activité parallèle.

2 La première conviction qui rassemblait ces intellectuels était le nationalisme ainsi que le rejet de l'assimilationnisme. Les yiddishistes de Kiev, tout comme les hébraïstes de Moscou, voulaient créer une culture nationale nouvelle. Défendant un nationalisme linguistique, ils définissaient le caractère national d'une culture par la langue utilisée et non par un contenu national identifiable. Cette nouvelle culture était donc nationale parce qu'elle était créée en yiddish et en hébreu, mais en aucun cas en russe. Cette conception du nationalisme était cependant anti-essentialiste et en rupture avec celle de Herder et de nombreux nationalistes juifs de l'époque. Pour les yiddishistes comme pour les hébraïstes, la langue n'était pas l'expression du caractère d'un peuple ou la quintessence de l'authenticité nationale, mais elle était une « membrane » « expansible à l'infini et semi-perméable ", " ouverte à la totalité de la culture humaine ». C'était un " entrepôt » qui devait s'enrichir de manière permanente par le biais de traductions et mettre à la disposition de ses locuteurs l'ensemble des traditions littéraires, modèles et canons issus des cultures du monde entier. Du fait de cette accumulation infinie, rendue possible par les échanges culturels, ainsi que de l'omniprésence du yiddish et de l'hébreu dans la vie quotidienne, les juifs pourraient alors créer, sans s'en rendre compte pour ainsi dire, une culture nationale nouvelle " aussi vaste que l'humanité », et qui resterait un espace de créativité séparé, mais ouvert.

3 Cette culture devait donc être simultanément juive et universelle. La quête d'universalité impliquait une rupture avec l'esthétique jusque-là prônée par une majorité d'intellectuels juifs à la suite de Bialik et An-ski. Pour ces derniers, la culture juive moderne et séculière à créer devait se nourrir des "traditions" nationales et chercher, collecter et adapter les formes « authentiques » de la culture nationale juive au monde moderne. Ils considéraient cette synthèse des traditions juives " authentiques » et de la culture européenne comme la seule manière d'éviter la désintégration culturelle et la perte d'identité qui menaçait le peuple juif. Par contraste, les modernistes de la Kultur-Lige et du Tarbut voulaient faire de la littérature juive un réceptacle de l'expérience humaine universelle. Afin d'éliminer tout «provincialisme» de la culture juive, ces derniers lancèrent un programme ambitieux de traduction de la littérature occidentale en yiddish et en hébreu, de Homère à Oscar Wilde. Rompant avec l'esthétique $\mathrm{du}$ " piocher, exposer, restaurer et styliser» (selon l'expression de Peretz Markish), ils voulaient aligner la littérature juive sur les standards européens et lui donner sa place dans la littérature européenne et mondiale.

4 L'ambition de concevoir une culture noble et de haute qualité (« high culture ») n'allait pas sans une certaine hostilité à l'égard de toutes les formes de culture " populaire » ou " de masse »: romances, théâtre de boulevard, romans d'aventure étaient des genres littéraires méprisés par ces modernistes. Cependant, leur quête de légitimité culturelle se doublait d'un souci de diffuser cette nouvelle culture juive à l'ensemble de la nation. La «culture-nation» qu'ils entendaient créer devait être démocratique et éliminer progressivement le fossé entre intelligentsia et peuple («folk»). Grâce à la levée des restrictions en matière d'éducation, de publication, de théâtre, le Tarbut et la KulturLige institutionnalisèrent l'alliance de toutes les formes culturelles pour diffuser cette 
nouvelle culture au plus grand nombre. L'éducation et la littérature pour enfants devinrent les vecteurs principaux de cette entreprise qui visait à « modeler les cœurs et les esprits». En unissant arts et éducation populaire (quand, par exemple, artistes et écrivains collaboraient pour créer des livres pour enfants), ces utopistes de la culture espéraient rendre accessible à toute la nation la " haute " culture qu'ils produisaient, sans en diluer la qualité. Leur ambition était ainsi de transformer les masses en intellectuels.

5 Enfin, le dernier principe essentiel de cette renaissance culturelle était la liberté individuelle de ses créateurs et l'autonomie du mouvement par rapport au politique. Dans de nombreux articles et professions de foi analysés par Moss, ces intellectuels (Dovid Bergelson notamment) liaient l'élaboration d'une culture moderne de haut niveau à la libération de l'individu juif. Cette libération passait d'abord par un refus catégorique de mettre l'artiste au service d'une cause politique. Malgré la très forte politisation de la société juive et l'engagement individuel de ces intellectuels dans tel ou tel courant du nationalisme juif, ces derniers insistaient sur la nécessité de créer des institutions purement culturelles, totalement autonomes de la sphère politique; et appelaient les partis politiques à soutenir cette autonomie et à respecter les lois propres à la création artistique, sans imposer de contenu politique. Toutefois, il ne suffisait pas de garantir l'autonomie institutionnelle de la culture; il fallait aussi encourager la liberté individuelle et la force créatrice de chacun. L'éducation des enfants occupait un rôle central dans cette renaissance culturelle, comme en témoigne l'explosion du nombre de jardins d'enfants, d'écoles et de collèges. L'enfant n'était pas conçu comme un sujet national en devenir auquel il fallait transmettre des valeurs nationales, mais comme une individualité en formation dont il fallait éveiller la créativité. D'où la place centrale accordée à l'esthétique et au développement des sens. L'éducation devait aussi encourager l'originalité et former un individu capable de penser indépendamment. La culture moderne juive devait ainsi être la somme de l'expression de ces individualités.

Moss explique dans la dernière partie de son livre comment ce projet de création d'une culture juive, moderne, séculière, universelle, totale, démocratique, institutionnalisée et autonome a été d'abord validé, puis récupéré par les autorités bolcheviques et enfin vidé de son sens et «bolchevisé ». Les intellectuels juifs eurent à faire un choix : rester et travailler pour les institutions soviétiques (par idéal, curiosité ou espoir); rester et travailler dans la clandestinité ; ou partir et réaliser leur rêve ailleurs, ce qui fut le choix de nombre d'entre eux. Cette étude invite donc à suivre le devenir de ce projet ambitieux en Pologne, à Berlin, où beaucoup émigrèrent après 1921, et aux États-Unis.

Ce travail fournit une relecture et une réinterprétation extrêmement fouillées et convaincantes, quoique parfois répétitives, d'une période et d'un phénomène culturels connus jusque-là superficiellement. Toutefois, en se limitant aux exemples de la KulturLige et du Tarbut, et en se focalisant sur Kiev et Moscou, Moss produit une vision biaisée de la renaissance de la culture juive en Russie. En se concentrant uniquement sur les modernistes yiddishistes et hébraïstes, il sous-estime, voire ignore, tout un pan de l'histoire culturelle des juifs de la Russie en révolution: l'expérience notamment des artistes d'origine juive qui travaillaient à Vitebsk à la même période et qui ont choisi soit de se rallier à la culture universelle, soit de continuer le projet nationaliste de collecte et de sublimation de la culture « authentique» du shtetl. Il ne faut pas oublier que les révolutions russes de 1917 ont catalysé la naissance ou la maturation d'autres projets culturels et d'autres formes d'identification juive, allant des plus nationalistes et 
«folkistes» aux plus russophiles et universalistes. De plus, en voulant souligner la parfaite cohérence du projet culturel des modernistes de Kiev, Moss tend à en gommer les incohérences et contradictions internes. Si, en effet, les écrivains yiddish de Kiev ont adopté une vision non essentialiste de la culture nationale et rejeté toute référence au passé et aux traditions juives, il n'en allait pas de même pour les artistes de la KulturLige qui ont abondamment utilisé le "folk-art» dans leurs créations (Ryback et Lissitzky notamment) et fondé explicitement la création d'un art national juif sur la réutilisation des motifs de l'art populaire juif. Dans le texte programmatique « Les voies de la peinture juive », publié par la Kultur-Lige en 1919, Ryback et Aronson élevaient Chagall en modèle du peintre juif moderne, justement parce qu'il était «le seul à avoir compris, apprécié et partiellement recréé poétiquement, le trait plastique populaire juif». La contribution fondamentale de Moss à l'écriture en cours d'une histoire culturelle des juifs d'Europe orientale au $\mathrm{xx}^{\mathrm{e}}$ siècle est en tout cas extrêmement stimulante et fondatrice. 